\title{
BUKU PEGANGAN GURU TK \\ DALAM PEMBELAJARAN BAHASA JAWA \\ DI DAERAH ISTIMEWA YOGYAKARTA ${ }^{1}$
}

\author{
Suharti dan Siti Partini \\ Universitas Negeri Yogyakarta
}

\begin{abstract}
Abstrak
Tujuan penelitian tahun ke 2 adalah Finalisasi materi Buku Pegangan Guru TK dalam Pembelajaran Bahasa Jawa di Daerah Istimewa Yogyakarta

Lokasi penelitian di Propinsi Daerah Istimewa Yogyakarta yang merupakan pusat Budaya Jawa. Pendekatan yang digunakan dalam penelitian ini adalah pendekatan kualitatif. Informan penelitian adalah Guru Taman Kanak-kanak baik di desa maupun di Kota, para pakar pendidikan bahasa Jawa, dan pakar pendidikan. Pengumpulan data dilakukan dengan wawancara mendalam dan Focus Group Discussion. Analisis data dilakukan dengan analisis induktif dengan memfokuskan pada penentuan isi buku pegangan guru TK.

Hasil penelitian menunjukkan bahwa (1) finalisasi materi Buku Pegangan Guru TK dalam Pembelajaran Bahasa Jawa di Daerah Istimewa Yogyakarta berisi butirbutir penting bahasa Jawa yang perlu diajarkan kepada anak usia TK adalah penggunaan bahasa Jawa sebagai sarana pendidikan sopan santun dalam pergaulan sehari-hari, pengenalan lingkungan, makanan tradisional, kesenian, dan adat istiadat; (2) Telah tersusun draf Buku Pegangan Guru TK dalam pembelajaran Bahasa Jawa dengan judul " Buku Piwulang Basa Jawa: Tuntunan kanggo Guru TK” berisi tema lingkungan, kasarasan, tetuwuhan lan kewan, dolanan/ lelagon, pangupajiwa/ pakaryan, dan wayang.
\end{abstract}

Kata kunci: buku pegangan guru TK, pembelajaran bahasa Jawa

\begin{abstract}
This article aims to finalizing the handbook of Kindergarten about Javanese language study in Yogyakarta. The setting of this research is in Yogyakarta province which is the center of Javanese culture. It was kulaitatif research. The informan was the kindergarten teachers in village or town, Javanese language and education expert. Data collected with interview and Focus Group Discussion. Data analized with inductive analize.

The research result were (1) finalization the handbook of Javanese language method in Kindergarten, (2) the study of the handbook with the title "Buku Piwulang Basa Jawa: Tuntunan kanggo Guru TK”.
\end{abstract}

Keywords: handbook, Javanese language teaching, kindergarten

\footnotetext{
${ }^{1}$ Penelitian Tahun ke 2, dibiayai oleh DIPA Universitas negeri Yogyakarta sesuai denganSurat Perjanjian Pelaksanaan Hibah Penelitian Nomor: 225a/H34.21/PL-HBL/2010 tanggal 30 April 2010.
} 


\section{PENDAHULUAN}

Bahasa Jawa merupakan bahasa daerah yang masih hidup dan digunakan sebagai bahasa komunikasi oleh masyarakat pendukungnya yang berada di daerah Jawa Tengah, Jawa Timur, Daerah Istimewa Yogyakarta, dan di manapun orang Jawa tinggal. Bahasa Jawa diajarkan di sekolah sebagai mata pelajaran muatan lokal wajib di tiga propinsi tersebut. Pada dasarnya pembelajaran bahasa Jawa adalah pembelajaran budaya. Artinya, berbahasa Jawa sekaligus menerapkan muatan-muatan budaya karena bahasa merupakan bingkai budaya dan sekaligus sebagai hasil budaya.

Bahasa Jawa tumbuh dan berkembang sebagai identitas orang Jawa yang sarat dengan berbagai nilai budaya yang adiluhung. Karenanya bahasa Jawa sebagai hasil budaya sekaligus sebagai sarana untuk mengkomunikasikan nilainilai budaya yang adiluhung tersebut kepada sesama pendukung budaya Jawa khususnya pada generasi mudanya.

Pada pendidikan formal di Daerah Istimewa Yogyakarta bahasa Jawa diajarkan dari SD sampai dengan SLTA, walaupun untuk SLTA baru mulai diajarkan sebagai muatan lokal wajib pada tahun 2004 atas dasar surat Kepala Dinas Pendidikan Propinsi DIY nomor 434/437 tanggal 3 Maret 2004. Kepala Dinas menginstruksikan agar Kepala Dinas Pendidikan Kabupaten/ Kota memasukkan mata pelajaran Bahasa Jawa sebagai muatan lokal pada pendidikan menengah dan berlaku mulai tahun ajaran 2004/ 2005.

Dengan demikian pembelajaran Bahasa Jawa mulai tahun ajaran 2004/2005, diajarkan mulai dari pendidikan dasar sampai perguruan tinggi, tetapi bagaimana dengan pembelajaran Bahasa Jawa di TK dan bagaimana pula penggunaan bahasa Jawa di masyarakat pendukungnya? Pembelajaran bahasa Jawa berkaitan erat dengan penggunaan Bahasa Jawa di masyarakat pendukungnya. Mata pelajaran bahasa Jawa hanya diberikan di sekolah dengan alokasi waktu dua jam pelajaran ditambah beberapa waktu dengan catatan bila anak menggunakan bahasa Jawa sebagai sarana komunikasinya di luar sekolah. Hasil pembelajarannya berkaitan erat dengan hasil pembiasaan penggunaan bahasa Jawa sejak kecil di dalam keluarga maupun lingkungannya (Suharti, dkk., 2001).

Fenomena penggunaan bahasa Jawa di dalam keluarga dan masyarakat di Daerah Istimewa Yogyakarta, telah menggejala ditinggalkan sebagai sarana komunikasi. Gejala ini dapat ditemukan di berbagai kegiatan di masyarakat ataupun di kampus yang memiliki prodi Pendidikan Bahasa Jawa. Di masyarakat penggunaan bahasa Jawa dihindari karena takut salah atau alasan lainnya, dan akhirnya mencari pengaman berkomunikasi, beralih ke Bahasa Indonesia yang pada dasarnya tidak banyak persyaratannya. Pada umumnya saat ini penggunaan Bahasa Jawa dirasa terlalu rumit harus mengingat unggah-ungguh yang ditandai dengan pemilihan tingkat tutur krama alus, ngoko alus, dan sebagainya. Berkaitan dengan adanya gejala mulai ditinggalkannya penggunaan bahasa Jawa saat ini Suwarna (2009) menyatakan bahwa (a) banyak orang tua Jawa tidak menggunakan bahasa Jawa dalam komunikasi sehari-hari; (b) dalam forum resmi Jawa, banyak pejabat yang menggunakan bahasa Indonesia dengan alasan forum resmi. Pertanyaannya adalah : Apakah bahasa Jawa tidak dapat digunakan dalam 
forum resmi ? Ironis. Pada umumnya pada awal-awal, mereka menggunakan bahasa Jawa, tetapi kemudian berganti bahasa Indonesia.karena takut salah, ragu, kurang yakin, kurang percaya diri, dan sebagainya. (c) pengambilan keputusan pragmatis yang keliru, banyak keluarga berbahasa Indonesia dalam berkomunikasi sehari-hari di lingkungan keluarganya. Mereka menyerahkan sepenuhnya pembelajaran bahasa Jawa di sekolah. Oleh karena itu di TK perlu diberikan pembelajaran berbudaya Jawa agar dapat digunakan sebagai sarana pembiasaan untuk persiapan mengikuti pembelajaran Jawa di SD. Untuk itu pada penelitian ini akan disusun buku pegangan guru TK dalam pembelajaran bahasa Jawa.

Penelitian ini merupakan penelitian kedua yang menghasilkan draf Buku Pegangan Guru TK dalam Pembelajaran Bahasa Jawa di Daerah Istimewa Yogyakarta, yang akan dilanjutkan penelitian pada tahap ketiga sehingga tersusun buku pegangan bagi guru TK untuk memberikan pembelajaran bahasa Jawa. Orang Jawa pada umumnya, tidak menginginkan budayanya termasuk di dalamnya bahasa Jawa hilang begitu saja. Oleh karena itu, wajib bagi warga Jawa untuk memelihara, melestarikan sesuai dengan kemampuannya. Harapannya agar anak-anak sebagai generasi penerus tidak asing berbahasa Jawa di leluhurnya sendiri, tanah Jawa. Untuk itu penggunaan bahasa Jawa sebagai kekayaan kearifan lokal perlu diupayakan pewarisannya kepada generasi muda sangat urgen, bahkan semakin dini (anak usia TK) semakin menguntungkan. Penggunaan bahasa Jawa di TK bergantung kepada kemampuan berbahasa gurunya. Kemampuan berbahasa Jawa guru TK tidak semua baik, bahkan boleh dikatakan lebih banyak yang sering mengalami keterbatasan dalam berbahasa Jawa, terutama sebagai sarana pembelajaran sopan santun (Suharti dan Siti Partini, 2009). Untuk itu para guru TK memerlukan buku pegangan dalam pembelajaran bahasa Jawa bagi anak didiknya.

\section{Metode Penelitian}

Penelitian ini menggunakan pendekatan kualitatif naturalistik, yaitu penelitian yang melihat kenyataan secara alamiah gejala-gejala penelitian yang sedang diteliti. Menurut Bogdan \& Biken (1982) penelitian kualitatif memiliki 5 ketentuan pokok, yaitu: (1) bersumber pada setting alamiah; (2) deskriptif, yaitu apa adanya yang berupa kata-kata; (3) lebih menekankan pada proses daripada hasil; (4) analisis datanya secara induktif; (5) perhatian pokok pada "pemaknaan" atau "meaning". Fokus penelitiannya adalah (1) finalisasi garis besar materi Buku Pegangan Guru TK dalam Pembelajaran Bahasa Jawa di Daerah Istimewa Yogyakarta, dan (2) penulisan draf Buku Pegangan Guru TK berdasarkan hasil penelitian tahap I yakni teridentifikasi penggunaan bahasa Jawa sebagai bahasa pengantar di TK, kemampuan berbahasa Jawa guru dan siswa TK, dan telah ditemukan aspek-aspek penting atau pokok-pokok bahasan yang diperlukan oleh anak usia TK yakni lingkungan, tetuwuhan lan kewan, tatakrama, dan wayang.

Pada penelitian tahap ini ditentukan kelompok dari kabupaten Sleman yang pada tahap I memberikan banyak informasi tentang teridentifikasikannya materi pembelajaran bahasa Jawa untuk anak TK. Pada diskusi I ini dikuti 10 orang guru TK baik guru yang PNS, yayasan, maupun guru honorer, nantinya simpulan informasi yang dihasilkan dari diskusi ini dibawa selanjutnya pada 
diskusi berikutnya yakni di kabupaten Kulon Progo, dan seterusnya sampai pada empat kabupaten dan satu kota terselesaikan. Adapun diskusi terbatas dengan para pakar ditentukan berdasarkan keahliannya yakni dalam pembelajaran Bahasa Jawa, pakar pendidikan anak usia dini, dan pakar psilogi pembelajaran.

Data penelitian didapat dari wawancara mendalam, pengamatan, dan hasil diskusi pada focus group discussion. Wawancara mendalam dan pengamatan juga dilakukan kepada para guru TK serta siswa dalam aktivitasnya sehari-hari di sekolah. Berdasar temuan dari berbagai wawancara dan observasi dilakukan penyususunan rancangan Buku Pegangan Guru TK dalam Pembelajaran Bahasa Jawa. Selanjutnya dilakukan langkah-langkah : (1) mereviu garis besar buku pegangan guru , (2) revisi, uji coba terbatas dan uji coba lapangan sampai diperoleh Buku Pegangan Guru TK dalam Pembelajaran Bahasa Jawa yang valid dan layak digunakan.

Analisis data penelitian ini dilaksanakan selama pengumpulan data dan setelah pengumpulan data selesai dengan analisis induktif. Analisis ini dengan melakukan kategorisasi dan perbandingan berkelanjutan sehingga dapat ditemukan tema dan dapat dirumuskan suatu kesimpulan berkaitan dengan rancangan buku pegangan guru TK dalam pembelajaran bahasa Jawa di Daerah Istimewa Yogyakarta.

\section{HASIL PENELITIAN DAN PEMBAHASAN Deskripsi Situasi Setting Penelitian}

Setting penelitian ini adalah pra sekolah atau TK di daerah Istimewa Yogyakarta yang terdiri atas empat kabupaten yakni Kabupaten Sleman, Gunung Kidul, Bantul, dan Kulon Progo, dan satu kota Yogyakarta. Pada tahap 2 ini diawali dengan diskusi terbatas dengan guru-guru TK di Kabupaten Sleman yang yang diikuti oleh 10 orang guru TK, terdiri dari guru TK Panti Dewi, TK Sumber, TK Sendangtirto, TK Jagatirto. Dari Kabupaten Bantul diskusi terbatas terdiri dari enam guru TK dari TK Kanutan, TK Sehati. Dari kelompok TK Bantul dilanjutkan diskusi terbatas dengan guru-guru TK di Kulon Progo dan TK dari kota Yogyakarta. Adapun dari pakar pendidikan bahasa Jawa dan budaya, serta pakar psikologi anak, dan pakar pendidikan anak usia dini didatangkan dari lingkungan kampus yakni dari Universitas Negeri Yogyakarta.

Perwakilan guru-guru di empat kabupaten satu dan kota adalah kelompok kelompok yang menjadi anggota diskusi terbatas I tentang finalisasi materi pembelajaran Bahasa Jawa bagi anak TK, yang telah dilaksanakan dengan baik dan dapat digunakan sebagai dasar penyusunan draf I Buku Pegangan Guru TK dalam Pembelajaran Bahasa Jawa di Daerah Istimewa Yogyakarta. Dalam diskusi tentang finalisasi materi pembelajaran bahasa Jawa, ada koreksi-koreksi tentang poin-poin yang akan diberikan kepada anak. Misalnya tentang konsep adil. Setelah materi teridentifikasi dilanjutkan dengan mengembangkan draf buku pegangan guru TK dalam pembelajaran bahasa Jawa. Bagi guru TK, dengan adanya diskusi tentang pembelajaran bahasa Jawa menyangkut materi dan cara penyampaiannya memberikan tambahan pengetahuan tentang pembelajaran bahasa Jawa untuk anak TK. Pembelajaran tersebut tidak hanya berwujud penggunaan bahasa Jawa tetapi termasuk di dalamnya budaya Jawa menyangkut 
semua aspek kehidupan orang Jawa pada umumnya, yang sebelumnya tidak pernah terpikirkan.

Penyusunan draf Buku Pegangan Guru TK dalam pembelajaran bahasa Jawa ini sangat ditunggu para guru TK pada umunya, khususnya para guru muda yang bersemangat untuk membelajarkan bahasa Jawa TK secara sungguh-sungguh. Hasil review dari para pakar yang diwujudkan dalam diskusi kecil memberikan pencerahan dan wawasan bagi tersusunnya draf buku pegangan ini.

\section{Hasil Penelitian dan Pembahasan}

Materi bahasa budaya Jawa yang perlu diajarkan untuk anak TK di Daerah Istimewa Yogyakarta yang terdiri dari empat kabupaten dan satu kota adalah agar (1) anak dapat berbahasa Jawa sederhana yang digunakan dalam kehidupan sehari-hari, kaitannya dengan sopan santun berbahasa Jawa; (2) anak belajar berbudaya Jawa lewat penggunaan bahasa Jawa dan pengenalan wujud budaya Jawa yang sesuai dengan usia anak TK yakni pengenalan lingkungan, busana, makanan, kesenian, adat istiadat yang maujud dalam pembiasaan, berbahasa, kognitif, fisik/ motorik, dan seni; (3) materi yang akan diajarkan kepada anak adalah unggah-ungguh berbahasa Jawa, yang sudah biasa dilakukan dan dikenal anak di dalam lingkungan keluarganya, pengenalan konsep sederhana gemi setiti ngati-ati, resikan, dsb.

Materi ini tidak dapat disajikan secara mandiri tetapi terintegrasi ke dalam tema: lingkungan, kasarasan, tetuwuhan lan kewan, dolanan/ lelagon, pangupajiwal pakaryan, dan wayang. Tema-tema ini disajikan dengan pengintegrasian pada tema yang terdapat dalam SKM yakni diri sendiri, lingkunganku, kebutuhanku, binatang, tanaman, rekreasi, pekerjaan, air- udaraapi, alat komunikasi, tanah airku, dan alam semesta. Anak diperkenalkan dengan berbagai hal tentang kejawaan supaya nantinya dapat mengenal budayanya sendiri secara baik. Pada pembelajaran tersebut diharapkan terjadi internalisasi budaya Jawa pada diri si anak secara baik pula, dan akhirnya terjadi pendarahdagingan hal budaya itu sendiri. Dengan demikian secara alami anak memperoleh pendidikan budayanya secara terarah. Pada kegiatan 1 terdapat indikator (1) Anak dapat melagukan lelagon Ésuk - ésuk”; (2) Anak dapat menyebut anggota keluarga masing-masing; (3) Anak dapat berpamitan kepada orang tua sebelum berangkat ke sekolah sesuai unggah-ungguh dikembangkan menjadi kegiatan pembelajaran dari kegiatan awal sampai kegiatan akhir. Yang dapat dilatihkan kepada anak TK adalah memberikan rasa senang pada anak karena anak diberikan kegiatan untuk menyanyi lelagon Ésuk - ésuk sambil berjoged. Sambil berjoged anak dilatih untuk menggerakkan anggota badannya. Gerak anggota badan termasuk pembiasaan agar badan anak biasa dilenturkan supaya tidak kaku supaya lemas.

Pada segi bahasa anak sambil bernyanyi diperkenalkan dengan kosa kata ésuk 'pagi', metu 'keluar' dan ibu; nyuwun pangestu 'mohon doa restu', sinau 'belajar', sabak 'alat tulis jaman dulu' - bapak; dan tengah - simbah- wayah sekolah pada tataran ini anak secara alamiah diperkenalkan dengan bentuk-bentuk seperti// ésuk - ésuk srengéngéné uwis metu ibu//nyuwun pangèstu kang putra badhé sinau// dan seterusnya akan terdengar bunyi yang berulang-ulang, anak 
akan dibiasakan untuk mengucapkan dan mendengarkan yang indah. Dengan jalan ini anak akan diperkenalkan urut-urutan bunyi yang sama yakni disebut purwakanthi 'sajak'.

Hal lain yang diperkenalkan pada kegiatan sambil bernyanyi dan berjoged adalah kosa kata ésuk - awan 'pagi-siang', awan -- srengéngé- tengah 'siang matahari - tengah'; di sini anak diperkenalkan dengan kosa kata bungah bungah-bungah, nyuwun pangestu. Simbah, ibu, dsb, hal lain yang dikenalkan kepada anak adalah adanya ragam tutur ngoko, Ésuk ésuk srengéngéné uwis metu ibu, dan tutur krama nyuwun pangèstu keng putra badhé sinau ibu. Di sini lewat menyanyi dan lenggak-lenggok si anak dilatih untuk mendengarkan adanya pengucapan bunyi yang sama pada bunyi [u], [ak], [ah]; adanya macam kosa kata, ragam tutur, dan adanya keterkaitan waktu ésuk dengan mangkat sekolah, nyuwun pangèstu, dan awan, srengéngé ana tengah, simbah, bungah-bungah keng wayah mantuk sekolah. Pada acara awal ini anak sudah dibawa dalam aspek pembiasaan, berbahasa, fisik motorik, dan seni (Diknas, 2005) dan juga sesuai dengan yang diamanatkan pada panduan pembelajaran anak TK oleh Pusdi PAUD bahwa pembelajaran pada anak usia dini harus mengaktifkan dan sekaligus memotivasi anak untuk belajar. Inilah yang dimaksudkan pembelajaran bahasa Jawa untuk anak TK terwujud dalam bentuk tematik yang integratif dengan tema-tema yang sudah ada dalam SKM dan sekaligus telah memperhatikan pada aspek yang harus di perhatikan dalam pembelajaran anak TK yakni pembiasaan, berbahasa, kognitif, fisik motorik dan seni.

Adapun dalam pembelajaran bahasa Jawa dalam kerangka budaya telah dilatihkan dengan menyanyi lelagon dolanan untuk memperkenalkan bunyibunyi berpurwakanthi, adanya ragam tutur ngoko - karma, mengenal berbagai kosa kata berkaitan dengan waktu, tugas sekolah, dan kewajiban anak untuk selalu hormat kepada orang tua yakni ibu bapak, simbah. Selain itu juga telah dilatihkan agar tetap melenturkan otot-otot, fisiknya dapat berkembang dengan baik dengan berlenggak lenggok sambil menyanyi. Secara alami anak dibiasakan untuk berfikir selalu tentang waktu, tugas dan kewajiban yang harus dilaksanakannya. Dan inilah yang nantinya diharapkan membentuk filter yang baik untuk dapat menyaring masuknya tindakan-tindakan yang kurang baik masuk ke dalam pikiran anak (Tajan Hadijayam 1957).

Berbeda sekali dengan pemikiran sebelumnya yang akan membelajarkan bahasa Jawa sesuai dengan kepentingan pembelajaran bahasa Jawa yang kurang memperhatikan keadaan anak TK, yakni dengan menentukan pentemaan: Unggah-ungguh ; Lingkungan; Panganan; Kesenian; Dolanan, dan Upacara adat.

Dari hasil diskusi terbatas tentang materi di atas yang akan diajarkan menyangkut finalisasi materi dari guru-guru TK mendapat koreksi tentang jenis permainan yang kurang aman, terlalu sulit atau belum dapat dimainkan oleh anak TK. Permainan tersebut seperti benthik dan gobag sodor belum dapat disampaikan untuk anak TK. Permainan benthik belum dapat diajarkan kepada anak TK karena permainan benthik menggunakan alat dua potong kayu agak panjang dan kayu kecil sebagai janak atau kayu yang dipukul. Untuk anak TK permainan tersebut masih berbahaya karena anak TK belum dapat mengendalikan dirinya, belum dapat membedakan antara keinginan dan kesanggupan diri untuk 
bermain. Jadi untuk permainan ini memang agak membahayakan bagi keselamatan para anak TK. Seperti tuturan Ibu Siwi seperti berikut.

"menawi benthik kaliyan gobag sodor menika kok kanggé laré TK taksih kawraten bu. Menawi benthik rak ngginakaken kajeng kanggé alatipun, la mangké menawi laré TK rak dèrèng mangertos menika mbebayani menapa boten, ingkang penting kepéngin dolanan waton nuthuk, mental ngéngingi sinten boten mangertos. Laré TK dèrèng saged mbédakaken dolanan menika mbebayani tumrap diri pribadinipun piyambak ugi sanèsipun"

'kalau benthik dengan gobag sodor untuk anak TK belum dapat diajarkan karena benthik menggunakan kayu sebagai alat permainannya. Anak TK belum dapat membedakan apakah permainan itu membahayakan untuk dirinya atau tidak dan juga untuk orang lain. Juga gobag sodor masih terlalu berat untuk diajarkan untuk anak TK, permainannya harus berlari-lari beberapa kali pada ukuran lapangan kira-kira panjang lima meter persegi ...'

Untuk makanan tradisional kalau daerah Bantul sudah beberapa tahun yang lalu pengenalan makanan tradisional dilakukan dengan memberikan makanan setiap hari Sabtu. Makanan ataupun jajan pasar tradisional diberikan secara bergantian sehingga anak mengenal makanan tradisionalnya secara bertahap. Itu diceritakan oleh Bu Sri seperti berikut.

" menawi panganan ingkang khas Jawi menika menawi daerah Bantul sampun dipunparingi déning tiyang sepuhipun sami iuran kanggé para siswa. Menawi mriki namung tumbas wonten peken."

'kalau makanan yang khas Jawa kalau daerah Bantul sudah diberi oleh orang tuanya beriur untuk anak-anaknya. Kalau di sini beli di pasar ...'

"... boten menapa-menapa bu wong ingkang tumbas bangsa gethuk, grontol, jagung, kala-kala pun tubasaken arem-arem, supados sami wareg. Mriki menika tetedhan ingkang rumiyin taksih kathah bu. Wonten uwi, mbili menika kathah menawi mriki. Dados laré-laré mriki taksih sami mangertos tur inggih sami purun maem ..."

'... tidak apa-apa bu orang yang dibeli hanya gethuk, thiwul, grontol, jagung, kadang-kadang dibelikan arem-arem supaya kenyang. Di sini makanan seperti $u w i$, mbili itu masih banyak, dan anak juga mau mencicipinya ...'

Ini sesuai dengan persyaratan yang diajukan oleh para ahli bahwa untuk TK permainan yang membahayakan belum dapat diajarkan (Pusdi PAUD, 2009). Begitu pula permainan gobag sodor untuk anak TK masih terlalu berat, mengingat gobag sodor memerlukan kegiatan fisik yang cukup berat, harus lari-lari dari jarak kira-kira bolak-balik pada ukuran kurang lebih lima meter mungkin dapat lebih dari tiga atau empat bahkan lima kali. Untuk anak TK permainan ini masih terlalu berat.

Begitu pula para pakar juga memberikan koreksi-koreksi yang tidak jauh berbeda dengan koreksi dari guru-guru TK tentang permainan, materi berbahasa Jawa yang terlalu banyak percakapannya dan terlalu panjang untuk ukuran anak TK. Yang terpenting bagi anak TK adalah mengaktifkan mereka untuk dapat 
bergembira sambil belajar mengenal sesuatu, belajar berpikir mengapa kenapa, secara sederhana. Pembelajaran anak TK diutamakan berujud permainan, nyanyian, dan belajar langsung. Yang penting bermain sambil belajar dan belajar sambil bermain atau bernyanyi sambil belajar dan belajar sambil bermain (Diknas, 2005) nantinya anak diharapkan sambil bermain, bernyanyi, mereka mendapatkan dasar pendidikan yang baik, mendarah daging. Pembelajaran bahasa Jawa tidak dapat disampaikan secara tematik tersendiri sesuai dengan tema yang diajukan pada awal diskusi tetapi akhirnya sesuai dengan hasil diskusi terbatas dengan para pakar dan guru-guru TK yang terlibat secara langsung di lapangan diwujudkan dalam pembelajaran pada anak TK. Berikut cuplikan contoh penyusunan yang masih berdasarkan tema pembelajaran bahasa Jawa yang dijabarkan dalam subtema seperti berikut.

1. Pamit marang bapak lan ibuné

a. Kompetensi :

Bocah bisa pamit sekolah marang bapak lan ibuné kanthi kurmat lan bocah bisa ngaturi salam marang bapak/ibu guru nalika tekan sekolah

b. Gambar :

1) Bocah (putri) pamit marang bapak lan ibuné kanthi kurmat.

2) Bocah ngaturi salam marang bapak ibu Guru

c. Pacalathon 'percakapan':

Tini : Pareng pak.... bu ...Tini bidhal sekolah

Bapak/ Ibu : Iya....., sing ngati-ati ya

Tini :Inggih

d. Materi Pembelajaran :

Anak dituntun untuk minta pamit kepada bapak ibunya kemanapun pergi.

Anak dibiasakan memberi salam kepada bapak ibu guru.

Bocah diajari /dikulinakaké pamit marang wong tuwané menawa arep

lelungan

Bocah diajari /dikulinakaké ngaturi salam nalika ketemu guru ana sekolahan

e. Gladhen 'latihan':

Guru : Wati, coba tirokna ngendikané bu Guru : Pareng pak bu Wati bidhal sekolah.

Wati : Pareng pak ibu Wati bidhal sekolah.

Bocah : (Bareng kabeh bocah sak kelas, terus digilirké ganti-ganti nganti bocah 5)

Guru : Saiki tekan sekolahan ngaturi salam karo bu Guru Sugeng énjing Bu Guru, .ayo ditirokke!

Bocah : (bocah nirokké bebarengan)

Guru : mengko yèn arep bali olehé ngaturi salam Sugeng siang pak

- bu Guru. Tirokké!

Bocah : (bocah padha nirokké bebarengan, terus digilir mbalèni nirokaké ganti ganti nganti bocah 5, bèn lanyah). 
Pengembangan tema pembelajaran di atas menggunakan bahasa Jawa dan hanya kompetensi istilah yang digunakan tetap berbahasa Indonesia. Format ini setelah di bawa ke lapangan didiskusikan denan guru-guru TK, sebagian besar menyatakan keberatan kalau semua penjelasannya juga menggunakan bahasa Jawa. Sebagian besar guru TK ini adalah tergolong guru TK yang masih muda tetapi memiliki kesadaran tinggi untuk membelajarkan bahasa Jawa terutama sebagai sarana pendidikan sopaan santun. Mereke ini kelompok guru TK yang memiliki kesadaran tinggi untuk mengajarkan bahasa Jawa di TK tetapi modal cekak. Artinya, mereka merasa kurang memiliki modal kemampuan berbahasa Jawa, ya karena memang kesempatan untuk pemerolehan bahasa - budaya Jawanya memang sangat minim, seperti berikut tuturannya.

Guru TK : "bu kami setelah mendengar penjelasan ibu tentang fungsi bahasa Jawa memang antusi unjtuk melaksanakan pembelajaran bahasa Jawa di TK tetapi kami memerlukan buku pegangan, kami betulbetul masih nol. Kalau buku pegangannya seperti ini semua penjelasan menggunakan bahasa Jawa kami kurang faham. Ada yang tahu tetapi sebagian besar lebih banyak yang tidak tahu. Usul buk, penjelasannya menggunakan bahasa Indonesia, materi tetap berbahasa Jawa."

Guru TK 2: ya bu dari omong-omongan ini tadi betul-betul memang bahasa Jawa sangat penting untuk dibelajarkan berbahasa Jawa, tetapi ya itu tadi, buku pegangan ini kalau sudah jadi kami dibagi ya bu"

Itulah usulan-usulan dari ibu guru TK yang masih muda sekali karena mereka ini termasuk sarjana penddikan yang baru saja lulus. Tetapi mereka guruguru yang memiliki idealisme tentang pendidikan sopan santun dan budi pekerti baik. Berbeda dengan tanggapan guru TK yang sudah senior, mereka memberikan pandangan tentang pembelajaran bahasa Jawa yang telah dilakukan sejak awal menjadi guru TK, tanggapannya seperti berikut.

Guru : ibu menika menawi kangge laré TK sampun wonten ingkang pas, boten kepanjangen, ugi boten kangèlen. Upaminipun menika "yèn ana tamu olèhé matur ngéné, ayo padha ditirokaké" menika kepanjangen, tur menawi guru menika ngendikan ngginakaken basa Jawi krama saé ngaten laré boten wonten ingkang ngertos."

Menurut ibu guru pada percakapan di atas yang sesuai, yang kurang menurut ibu guru merupakan saat yang tepat untuk membelajarkan bahasa Jawa sebagai sarana pendidikan sopan santun. Harus telaten dan menurut ibu guru harus juwèh 'harus telaten membetulkan kekurangtepatan bahasa Jawa anak' pendapat ibu guru TK tersebut sejalan dengan hasil penelitian Suharti (2001) yang menyatakan bahwa mahasiswa yang berbahasa Jawa-nya bagus adalah mahasiswa yang sejak kecil oleh orang tuanya dibiasakan untuk berbahasa Jawa krama kepada yang lebih tua, kepada kakek - nenek dan bapak-ibunya. Jadi dalam percakapan tersebut dalam diri siswa terjadi proses otomatisasi berbahasa Jawa krama. Pada kesempatan ini sebenarnya siswa telah mengalami proses pendidikan budaya secara sederhana tentang penerapan sopan santun berbahasa 
Jawa secara sederhana sesuai dengan kemampuan siswa TK tersebut. Sementara kebanyakan TK anak dibiarkan berbahasa Indonesia dan kadang menggunakan bahasa Indonesia yang campur aduk sesuai keperluannya. Siswa berkembang penggunaan bahasanya secara formal pada saat terjadinya proses pembelajaran.

Ini sejalan dengan arah pendidikan bahasa Jawa diarahkan kepada terjadinya transfer nilai-nilai budaya di dalam kehidupan berbudaya Jawa. Bahasa Jawa sebagai bagian tak terpisahkan dari kebudayaan bangsa Indonesia karenanya pembinaan dan dan pengembangannya tetap dalam bingkai keindonesiaan. Artinya, pembinaan dan pengembangan bahasa Jawa harus dilakukan seiring dengan pembinaan dan pengembangan bahasa Nasional. Bahasa Jawa tumbuh sebagai identitas diri dengan tetap mempertahankan nilai-nilai luhur yang terkandung di dalamnya, dan bahasa Indonesia tumbuh sebagai perekat bangsa. Selain itu, bahasa Jawa tidak dapat dilepaskan dari budaya Jawa. Bahasa Jawa tidak sekedar artefak budaya Jawa tetapi merupakan bingkai budaya Jawa. Bahasa Jawa sebagai bahasa Daerah memiliki tiga fungsi utama yakni fungsi kebudayaan, komunikasi, dan pendidikan. Fungsi kebudayaan diarahkan untuk tujuan pelestarian kebudayaan, pengembangan kebudayaan, dan inventarisasi kebudayaan. Fungsi komunikasi diarahkan pada untuk tujuan alat perhubungan di dalam keluarga dan masyarakat Jawa, adapun fungsi pendidikan diarahkan untuk dua hal, yaitu kultural dan edukatif. Tujuan edukatif diarahkan seseorang dapat menggunakan bahasa Jawa secara baik dan benar dan untuk pemerolehan nilainilai budaya (muatan lokal) untuk keperluan pembentukan kepribadian dan identitas bangsa. Tujuan kultural diharapkan diharapkan agar melalui pendidikan dapat digali dan ditanamkan kembali nilai-nilai budaya Jawa sebagai upaya untuk membangun identitas dan menanamkan filter dalam menyeleksi pengaruh budaya luar. (Tardjan Hadidjaja, 1957; Suharti, 2005).

Butir-butir penting dari bahasa Jawa yang perlu diajarkan kepada anak usia TK adalah penggunaan bahasa Jawa sebagai sarana pendidikan sopan santun dalam pergaulan sehari-hari, pengenalan lingkungan, busana, makanan tradisional, kesenian, adat istiadat. Pendidikan sopan santun dlakanakan guru pada setiap perilaku atau pada setiap kesempatan, dapat di dalam kelas maupun di luar kelas. Penerapan pendidikan sopan santun ini menurut guru memiliki porsi yang paling banyak karena berada di mana-mana di setiap kesempatan. Penerapan lainnya dapat lewat media permainan, sewaktu makan, jalan-jalan dan sebagainya. Pendidikan bahasa Jawa dalam kerangka budaya ini antara lain diarahkan untuk mendidik siswa memiliki watak utama seperti disebut di atas. Mendidik siswa berwatak utama tidak semudah membalik telapak tangan. Menurut Ki Hadjar Dewantoro (1977) mendidik adalah suatu proses tuntunan. Pendidikan dimaksudkan untuk menuntun segala kekuatan kodrat yang ada pada anak-anak itu, agar mereka sebagai manusia dan sebagai anggota masyarakat dapat mencapai keselamatan dan kebahagiaan yang setinggi-tingginya. Bahasa sebagai sarana pendidikan juga disadari oleh kelompok guru TK yang berbahasa Jawa secara baik, betapa besar manfaat pendidikan bahasa Jawa kepada anak didik dan sebetulnya juga disadari untuk diri sendiri. Dengan menggunakan bahasa Jawa sesuai dengan unggah-ungguh dapat terhindar dari percecokan dengan orang lain karena pada dasarnya pemilihan bentuk unggah-ungguh didasarkan pada konsep 
sopan santun yang mendasarkan pada sesuatu yang seimbang ibarat timbangan, yang diwujudkan alam ungkapan deduga, prayoga, watara, dan reringa (Darusuprapta, 1990; Suharti, 1998).

Berdasarkan hasil diskusi terbatas dengan guru-guru TK di empat kabupaten dan pakar pakar berkaitan dengan draf buku pegangan pembelajaran bahasa Jawa yang diusulkan, saran-saran dari lapangan dan dari para pakar tersususun Draf Buku Pegangan guru TK dalam pembelajaran Bahasa Jawa yang direncanakan akan diberi judul "Buku Piwulang Basa Jawa, Tuntunan kanggo Guru TK”.

\section{Daftar Pustaka}

Conny R,. Semiawan. 2008. Belajar dan Pembelajaran Prasekolah dan Sekolah Dasar, Indonesia : Indeks.

Coon, Dennis, John O. Mitterer. 2007. Introduction To Psychology, Gateways To Mind and Behavior. Thomson Wadsworth.

Darusuprapto, 1985, Ungkapan Tradisional Sebagai Sumber Informasi Kebudayaan, Yogyakarta, Depdikbud. 1990.wulangreh Anggitan Dalem Sri Pakubuwana IV, cetakan IV. Surabaya: PT Citra Jaya Murti.

Hurlock, Elizabeth B. 1993. Suatu Pendekatan Sepanjang Rentang Kehidupan. Jakarta : Penerbit Erlangga.

Hurlock, Elizabeth B. 1996. Perkembangan Anak Jilid I (Terjemahan Meitasari Tjandrasa). Jakarta : Penerbit Erlangga.

Jalongo, Mary Renck, et al. 2002. "Using Wordless Picture Books to Support Emergent Literacy", Dalam Early Childhood Education Journal. Vol 29. No.3, Spring 2002.

Koentjaraningrat, 1990. Kebudayaan Jawa. Yogyakarta, Gama University Press , 1996. Pengantar An tropologi I. Yogyakarta: Rineka Cipta.

Papalia, Olds, and Ruth Duskin Feldman , 2001, Human Development (eight edirion) Boston : McGraw-Hill Higher Education.

Santrock, John. W. 1997. Life-Span Development (sixth-edition).Dubuque : Brown \& Bencmark.

Sri Harti Widyastuti.2002. Kearifan Lokal Masyarakat Jawa dalam Teks Jawa Abad XVIII s/d Abad XIX. Laporan Penelitian. Yogyakarta. Universitas Negeri Yogyakarta.

Suharti.1998. Perilaku Berbahasa Jawa Mahasiswa Ekspresi Lisan Program Studi Pendidikan bahasa Jawa FPBS IKIP YOGYAKARTA. Jakarta: Pascasarjana (desertasi)

Suharti, dkk. 2004. Model Pembelajaran Bahasa jawa di SMA. Yogyakarta: Lemlit UNY.(penelitian)

Suharti. 2005. Peran Pendidikan Bahasa Jawa dalam Pembinaan Perilaku Bangsa. Yogyakarta; UNY (pidato pengukuhan)

Suharti, dkk., 2006. Apresiasi Budaya. Yogyakarta: FBS UNY. (Naskah)

Suwarna, 2009, Bahasa Jawa Berbasis Keluarga, dalam harian Kedaulatan Rakyat, Saptu Wage 29 Agustus 2009 , halaman 15, Yogyakarta. 